\title{
O INSTITUTO TERRAS DE MARINHA SOB UM OLHAR CONTEMPORÂNEO DA GESTÃO E POLÍTICA PÚBLICA.
}

\author{
THE MARINE LAND INSTITUTE UNDER THE \\ CONTEMPORARY LOOK OF PUBLIC POLICIES.
}

Fabiana Arend Branco ${ }^{1}$

\begin{abstract}
RESUMO: Frente às limitadas e controversas interpretações sobre o tema, bem como sua importância social e econômica no âmbito da gestão pública, este artigo tem como objetivo explicitar o que é o instituto denominado terrenos de marinha e se está atualizado, ou não, frente aos conceitos de gestão e política pública contemporâneos. Para isso, inicialmente, trouxe-se um resgate bibliográfico da natureza jurídica e origem histórica dos terrenos de marinha, bem como dos conceitos de gestão e políticas públicas, para então, serem contrastá-los. Ao final deste artigo, foi possível identificar o desuso da política originária dos terrenos de marinha e a transformação ao longo do tempo de seus princípios e objetivos, ao passo que não foi acompanhada por atualizações legislativas. Desse modo, carece-se de uma gestão com maior autonomia aos Municípios, bem como de políticas consistentes e condizentes com o cumprimento da função social dos terrenos de marinha.
\end{abstract}

palavras-chave: Terrenos de marinha,Gestão Pública, Política Pública.

ABSTRACT: In face of the limited and controversial interpretations on the theme, as well as its social and economic importance within the scope of public management, this article aims to explain what the marine lands rules are and whether it is updated, or not, regarding the concepts of contemporary management and public policy. For this, initially, a bibliographic rescue of the legal nature and historical origin of the marine lands was brought, as well as the concepts of management and public policies, so that they could then be contrasted. At the end of this article, it was possible to identify the disuse of the original marine lands policy and the transformation over time of its principles and objectives, while it was not followed by legislative updates. Thus, there is a need for management with greater autonomy for the Municipalities, as well as consistent policies with the fulfillment of the social function of the marine lands.

KEYwORds: Marine Lands,Public Administration, Public Policies.
1

Advogada Sócia do escritório da Fonte, advogados. Especialista em Direito Imobiliário e Mestra em Gestão de Políticas Públicas pela Universidade do Vale do Itajaí - Univali. 


\title{
1 INTRODUÇÃO
}

Os terrenos de marinha surgiram há aproximadamente 337 anos, ainda no Brasil colônia, quando a coroa Portuguesa teve de proteger as praias de invasões inimigas, investindo na colonização desse território com a fixação permanente de pessoas em povoados ao longo da costa brasileira ${ }^{1}$. Desde então, a construção do conceito ideal oscilou entre os interesses militares, o potencial lucrativo dos terrenos, até, finalmente, ser calcada sobre o próprio valor da terra.

Passados três séculos do surgimento da primeira política pública envolvendo terrenos de marinha, foi em 1946, através do Decreto-lei no 9.760, que se positivou o conceito jurídico deste instituto ${ }^{2}$ e que permanece em vigor até os dias atuais.

\begin{abstract}
“São terrenos de marinha, em uma profundidade de 33 metros medidos horizontalmente, para a parte da terra, da posição da linha do preamar-médio de $1831^{3}$, os situados no continente, na costa marítima e nas margens dos rios e lagoas, até onde se faça sentir a influência das marés e os que contornam as ilhas situadas em zona onde se faça sentir a influência das marés".
\end{abstract}

Ocorre que, não só seu objetivo e função social sofreram consideráveis alterações ao longo dos anos, passando de uma norma jurídica que originalmente visava assegurar às populações e à defesa nacional o livre acesso ao mar e as áreas litorâneas, em face das preocupações da administração da Coroa, ${ }^{4}$ para a de assegurar a fixação das comunidades tradicionais em locais de uso sustentável, apoiando o desenvolvimento local e a ordenação do uso racional e sustentável dos recursos naturais disponíveis na orla marítima e fluvial; como também a forma de gestão pública mudou, passando de uma patrimonialista para uma gerencial. De um período colonial em que o Estado vinculava-se ao gestor a, hoje, uma república institucionalizada e em processo de modernização. ${ }^{5}$

Os imóveis localizados em terrenos de marinha constituem bens da União, conforme previsto no art. 20, inciso VII, da Constituição Federal Brasileira. Considerando a vasta extensão de áreas de marinha pertencentes à Coroa, vislumbrada com a potencial fonte de arrecada-

1 LIMA, A. J.; CHICUTA K.; JACOMINO, S. Terrenos de Marinham Instituto Jurídico tipicamente brasileiro. IRIB. Sergio Antônio Fabris Editor. Porto Alegre, 2003, p. 30.

2 Instituto: o que se estabelece como regulamento, regra ou regime.

3 De acordo com Zimmermann (1993, p. 30), a partir da Ordem de 12 de julho de 1831

se fixou a preamar média tendo um determinado período de tempo como base para a demarcação: "o período de tempo entre duas luas novas, correspondente a 29 dias, 12 horas e 44 minutos, observam-se a maior e a menor enchente da maré de uma lunação, e toma-se a linha média. A partir desta linha, medem-se 15 braças, ou seja, os 33 metros em direção à terra firme".

4 LEIVAS, L. C. P. Terrenos de Marinha e Terrenos da Marinha: do patrimônio nacional às origens do patrimônio naval. Revista Marítima brasileira/ serviço de documentação geral da marinha, Rio de Janeiro, v. 10/12, 1977, p. 113.

5 BRESSER-PEREIRA, L. C. Democracia, Estado Social e Reforma Gerencial. RAE. São Paulo, v.50, n.1, jan/mar, 2010. 
ção financeira para os cofres públicos, passou a comercializá-las com particulares, sob a forma de ocupação e aforamento, algumas faixas de terrenos de marinha ou dos terrenos acrescidos de marinha, servindo a linha da preamar média de 1831 como a referência para as medidas. ${ }^{6}$

Assim, de acordo com Rodrigues (2012, p.93) são mais de 8.500 $\mathrm{km}$ de zona costeira, onde se encontra $1 / 4$ da população brasileira (42 milhões de habitantes aproximadamente), com cerca de 700.000 imóveis considerados como bens da união, com patrimônio estimado em $\mathrm{R} \$$ 192.000.000.000.

Pouco estudado pela doutrina pátria, esse instituto atualmente encontra-se redigido, basicamente, pela Constituição Federal Brasileira, pelo Decreto-Lei no 9.760/46 e pelas Leis no 9.636/98, 13.240/15, 13.139/15, $10.257 / 01$ e a mais recente 14.011/20. Ao questionar como que um arcabouço legal, ligado a aspectos históricos seculares se comporta frente a uma gestão pública contemporânea, o presente estudo tem como objetivo interpretar de forma concisa o acervo de materiais que versam sobre o tema, buscando contextualizar o instituto terrenos de marinha e os aspectos que compõe a gestão pública contemporânea, tendo como objetivo responder as seguintes perguntas: $\mathrm{O}$ que são terrenos de marinha? Tal instituto encontra-se atualizado em face dos conceitos contemporâneos de gestão e políticas públicas?

\section{DOS TERRENOS DE MARINHA}

No Primeiro Reinado do Brasil, mais precisamente no ano de 1818, foi criado o instituto jurídico dos terrenos de marinha e seus acrescidos, estabelecendo uma faixa territorial de 15 braças craveiras (33 metros) para o lado de terra a partir da linha até onde chegavam às águas do mar. ${ }^{7}$

A justificativa para a criação desta norma jurídica, cuja prática já vinha desde o início da colonização brasileira, foi a de assegurar às populações e à defesa nacional o livre acesso ao mar e às áreas litorâneas, em face das preocupações da Administração da Coroa, decorrentes das edificações que estavam sendo construídas na orla marítima da cidade do Rio de Janeiro ${ }^{8}$.

Essa mesma justificativa é trazida por Romiti (2001, p.10):

"A razão principal para a instituição foi militar, secundariamente, servir como fonte de renda. Buscou-se a manutenção da faixa livre na borda do mar, sem construções outras que bélicas, pronta para o livre deslocamento de tropas na hipótese de defesa urgente contra desembarques, seja de piratas, seja de forças regulares do país inimigo.

6 OLIVEIRA, J. E. A. de. Aforamento e cessão dos terrenos de marinha. Ed. Imprensa Universitária do Ceará, Fortaleza, 1966, p.44.

7 OLIVEIRA, J. E. A. de. Op. Cit., p.43

8 LEIVAS, L. C. P. Op. Cit., p. 114. 
Para Passos (2013, p. 48) a confirmação da verdadeira intenção do governante com a criação do instituto está no Manual de Regularização Fundiária em Terras da União, editado pelo Ministério do Planejamento, Orçamento e Gestão (março-novembro 2006, p. 101), na resposta à pergunta: Por que a União tem patrimônio imobiliário? resumindo com clareza, aquele momento histórico:

“Os próprios interesses da defesa do território, no início da colonização, representavam a garantia do monopólio de exploração das riquezas naturais da Colônia pela Coroa. Por isso, o início da terra pública, no país, está assentado na propriedade do Rei sobre o território brasileiro. E, desde então, a terra foi distribuída conforme os interesses do governante em uma relação promíscua com os particulares - a distribuição de sesmarias."

Já para Machado (2010, p. 132) a preocupação com a defesa do litoral e das zonas adjacentes foi uma das preocupações que levou a Coroa Portuguesa a reservar as marinhas.

“[...] Essa era a ideia, manter nos diversos países que instituíram esta limitação ao direito de propriedade. Essa Diretriz permanece, mas acrescida da ideia de livre acesso ao mar e de proteção ao meio ambiente litorâneo."

Ao longo dos anos, essa lógica nao apenas pautou a relação governo-sociedade como também levou o Estado a adquirir imóveis dominiais como forma de investimento - prática corrente entre os particulares. ${ }^{9}$ Talvez o grande interesse em enunciar os terrenos de marinha no rol dos bens públicos esteja relacionado ao aspecto patrimonial, pela riqueza de sua contribuição para o domínio público e renda arrecadada pelo Tesouro dos foros e laudêmios devidos pelos concessionários. ${ }^{10}$

De acordo com o Ministério do Planejamento, os terrenos de marinha tem o cumprimento da função social de assegurar a fixação das comunidades tradicionais em locais de uso sustentável, áreas vazias urbanas para provisão habitacional e apoio ao desenvolvimento local e regularização em áreas de interesse social, tendo como objetivo a ordenação do uso racional e sustentável dos recursos naturais disponíveis na orla marítima e fluvial. ${ }^{11}$

9 PASSOS, T. Terras de marinha, Leme/SP: Mundo Jurídico, 2013, p. 48. 10 CAVAlCANTI, T. B. Tratado de Direito Administrativo. 5. ed. Rio de Janeiro: Freitas Bastos, 1964.

11 BRASIL, Gestão do Patrimônio Imobiliário: Terrenos de Marinha. Disponível em: <http://www.planejamento.gov.br/apresentacoes/apresentacoes-2015/apresentacao-cdrsenado-090915.pdf>. Acesso em: 04 dez. 2015. 
É nesta linha de raciocínio que o art. 225 da Constituição Federal ${ }^{12}$ prevê a utilização legal e segura da zona costeira brasileira. Trata-se da defesa e preservação pelo Poder Público e pela coletividade, de um bem público (o meio ambiente ecologicamente equilibrado), cujo modo de apropriação dos seus elementos constituintes, pela sociedade, pode alterar as suas propriedades e provocar danos ou, ainda, produzir riscos que ameacem a sua integridade. A mesma coletividade que deve ter assegurado o seu direito de viver num ambiente que lhe proporcione uma sadia qualidade de vida, também precisa utilizar os recursos ambientais para satisfazer suas necessidades. Na vida prática, o processo de apropriação e uso dos recursos ambientais não acontece de forma tranquila. Há interesses em jogos e conflitos (potenciais e explícitos) entre atores sociais que atuam de alguma forma sobre os meios físico-natural e construído, visando o seu controle ou a sua defesa. ${ }^{13}$

Portanto, é na tensão entre a necessidade de assegurar o direito ao meio ambiente ecologicamente equilibrado, como bem de uso comum da população e a definição do modo como devem ser apropriados os recursos ambientais na sociedade, que o processo decisório sobre a sua destinação (uso, não uso, quem usa, como usa, quando usa, para que usa, etc) opera. ${ }^{14}$

Impõe-se atentar para o fato de que os terrenos de marinha não podem ser equiparados às praias, como pode parecer à primeira vista. A Lei $\mathrm{n}^{\mathrm{o}} 7.661 / 88$, responsável pela instituição do Plano Nacional de Gerenciamento Costeiro, em seu art. 10, $\S 3^{\circ}$, preceitua que:

"[...] entende-se por praia a área coberta e descoberta periodicamente pelas águas, acrescida da faixa subsequente de material detrílico, tal como areias, cascalhos, seixos e pedregulhos, até o limite onde se inicie a vegetação natural, ou, em sua ausência, onde comece um outro ecossistema".

Portanto, extrai-se a conclusão de que as praias têm dimensão variável, ou seja, o critério legal demarcador dos terrenos de marinha (33 metros a partir da linha da preamar-média de 1831) pode ultrapassar a faixa da praia, bem como esta também pode ultrapassá-los. ${ }^{15}$

12 Art. 225: todos têm direito ao meio ambiente ecologicamente equilibrado, bem de uso comum do povo e essencial à sadia qualidade de vida, impondo-se ao Poder Público e à coletividade o dever de defendê-lo e de preservá-lo para as presentes e futuras gerações.

13 QUINTAS, J. S. Educação No Processo De Gestão Ambiental: Uma Proposta De Educação Ambiental Transformadora E Emancipatória. Brasília, Edições IBAMA, 2002, p.2.

14 QUINTAS, J. S. Op. Cit., p. 2.

15 COIMBRA, G. Q.; KRHLING, A. Terrenos de marinha e acrescidos: novas perspectivas para o debate.2015. Disponível em: $<$ http://docplayer.com.br/7079474-Terrenos-de-marinha-e-acrescidos-novas-perspectivas-para-o-debate-1.html>. Acesso em:11 fev.2016 
A Constituição Federal dispõe sobre os terrenos de marinha em seu art, 20, inciso VII, que os classifica como bens da União e no $\S 2^{\circ}$, do artigo 49, do Ato das Disposições Constitucionais Transitórias, que dispõe sobre os direitos dos ocupantes de terrenos de marinha inscritos até a época da promulgação da Constituição Federal.

Quanto à legislação infraconstitucional, merece destaque:

(i) O Decreto-Lei no 9.760/46, que dispõe, de modo geral, sobre os bens imóveis da União;

(ii) A Lei no 9.636/98, que dispõe sobre a regularização, administração, aforamento e alienação de bens imóveis de domínio da União;

(iii) A Lei no $13.240 / 15$, que trata sobre a administração, a alienação, a transferência de gestão de imóveis da União e seu uso para a constituição de fundos. Tal norma foi um divisor de águas na cobrança das taxas no setor imobiliário, alterando pontos significativos com relação as alíquotas das taxas de ocupação e laudêmio até então praticadas;

(iv) A Lei n $\mathrm{n}^{\mathrm{o}} 13.139 / 15$, que dispõe sobre o parcelamento e a remissão de dívidas patrimoniais com a União;

(v) A Lei $\mathrm{n}^{-1}$ 10.257/01, mais conhecida como o Estatuto das Cidades, a qual determina que o plano diretor municipal deve estabelecer quais são os critérios para o exercício das funções sociais da propriedade e;

(vi) A Lei n 14.011/20, publicada no Diário Oficial da União (DOU) em 12/06/2020, que moderniza e simplifica o processo de venda dos imóveis da União sem utilidade à Administração Pública Federal. Entre as novidades trazidas pela nova legislação, estão: o certame virtual, a avaliação baseada em métodos estatísticos, a simplificação da remição de foro, a livre manifestação de interesse na aquisição de imóveis da União, a venda direta com a participação de corretores e a alienação de imóveis em lotes.

Além desses diplomas legislativos, pode-se contar uma série de decretos, portarias e instruções normativas que abordam sobre o assunto.

A ausência de demarcação e constituição das enfiteuses administrativas fez com que a ocupação dos terrenos de marinha fosse uma realidade. Este título precário e resolúvel de posse é considerado como mera tolerância administrativa e pressupõe o efetivo aproveitamento do terreno pelo ocupante, outorgado sempre - após a análise da conveniência e oportunidade administrativa.

Segundo o art. 64 do Decreto-Lei citado no item (i) acima, bens imóveis da União que não são utilizados em serviços públicos poderão, qualquer que seja sua natureza, ser alugados, aforados ou cedidos. Nesse caso, as receitas auferidas nessas condições são denominadas de receitas patrimoniais e cabe ao Governo Federal por meio da Secretaria do Patrimônio da União (SPU), órgão vinculado diretamente ao 
Ministério do Planejamento, Desenvolvimento e Gestão, a fixação do valor locativo e a cobrança desses recursos.

Tais receitas não são consideradas tributos, mas contraprestações devidas pelos particulares pelo uso privilegiado de bens que são de todos, sendo eles:

Taxa de ocupação: A inscrição de ocupação é um dos instrumentos de destinação de imóveis da União. Segundo a SPU, trata-se de um ato administrativo precário, ou seja, pode ser revisto a qualquer tempo e pressupõem o efetivo aproveitamento do terreno pelo ocupante. $\mathrm{O}$ art. $1^{\circ}$ do Decreto-Lei $n^{\circ}$ 2.398, de 1987 define que a taxa de ocupação corresponda a $2 \%$ do valor do domínio pleno do terreno, excluída as benfeitorias;

Foro: O aforamento consiste, o art. 123 do Decreto $n^{\circ}$ 9.760/46, alterado pela Lei $\mathrm{n}^{\mathrm{o}}$ 13.240/15, em um contrato por meio do qual a União concede ao privado $83 \%$ do domínio útil do imóvel e mantém a posse dos $17 \%$ remanescentes. Nesse caso, essa natureza se dará quando coexistirem a conveniência de radicar-se o indivíduo ao solo e a de manter-se o vínculo da propriedade pública $(\S 2 \stackrel{\circ}{\circ}$, do art. 64 do decreto citado). Trata-se de uma receita patrimonial paga anualmente, ao qual corresponde $0,6 \%$ do valor do pleno domínio do terreno, excluídas as benfeitorias (art. 101 do Decreto $n^{0} 9.760$, de 1946, alterado pela Lei $n^{\circ}$ 7.450, de 1985) e,

Laudêmio: o Decreto-Lei nº 2.398/87, alterado pela Lei nº 13.240/15, define laudêmio como uma taxa de $5 \%$ correspondente a transferência onerosa, entre vivos, do domínio útil e da inscrição de ocupação de terreno da União ou de cessão de direito, tais como: compra e venda, promessa de compra e venda, permuta, dação em pagamento, fusão e integralização de capital social. Uma demonstração feita pelo Sindicato da Habitação do Rio de Janeiro (SecoviRio, 2016) ilustra a mudança trazida pela Lei $\mathrm{n}^{\mathrm{o}}$ 13.240/15: um apartamento de $140 \mathrm{~m}^{2}$ na praia de Copacabana com preço de venda de $\mathrm{R} \$ 2.210 .000,00$ teria laudêmio de $\mathrm{R} \$ 51.000,00$ pelo padrão anterior. Agora, esse valor cai para $\mathrm{R} \$$ $33.100,00$.

Assim, se outrora as faixas de terras destinadas às marinhas serviam à defesa e ao escoamento da produção nacional à Coroa, ora cingiram-se a importante fonte de receita federal, a propiciar no ano de 2018, por exemplo,receita ao Serviço do patrimônio da União de aproximadamente $\mathrm{R} \$ 391.000 .000,00 .{ }^{16}$

16 MORAES, L. Com crescimento de $81 \%$ em sete anos, taxas de Marinha são questionadas na Justiça. 2019. Disponível em: <https://jc.ne10.uol.com.br/canal/economia/ pernambuco/noticia/2019/08/11/com-crescimento-de-81_porcento-em-sete-anos-taxas-da-marinha-sao-questionadas-na-justica--385266.php>. Acesso em: 10 ago. 2020. 
Ademais, existe um grande interesse sobre os terrenos de marinha, especialmente os localizados em áreas urbanas desenvolvidas ou com perspectivas de desenvolvimento. Os terrenos de marinha e seus acrescidos localizados nas áreas urbanas, de uma maneira geral, sofrem pressões quanto à sua ocupação, ampliando os conflitos. A escassez de terra urbana exige atenção redobrada dos órgãos fiscalizadores, sendo necessária avaliação sócio espacial local e da infraestrutura instalada para garantir a preservação ambiental, por vezes ignorada diante das especulações imobiliárias. ${ }^{17}$

\section{DA GESTÃO E POLÍTICA PÚBLICA}

As políticas desenvolvidas pelo Estado, normalmente, são consideradas como ações públicas e têm como referência a utilização de recursos públicos (oriundos da arrecadação de impostos, receitas provenientes de organizações e/ou serviços de utilidade pública e empréstimos concedidos para alcançar a finalidade do bem-estar do todo social). O que implica considerar que as transferências de recursos feitas pela população para o Estado (através do pagamento e impostos e outras taxas) para que este as realoque de forma universal (através de ações públicas de distribuição e/ou redistribuição) deveriam garantir o atendimento dos interesses e necessidades dessa população. ${ }^{18}$

Segundo destacado por Teixeira (2002, p. 2):

[...] políticas públicas são diretrizes, princípios norteadores de ação do poder público; regras e procedimentos para as relações entre poder público e sociedade, mediação entre atores da sociedade e do Estado. São, nesse caso, políticas explicitadas, sistematizadas ou formuladas em documentos que orientam ações que normalmente envolvem aplicações de recursos públicos [...] Devem ser consideradas também as "não-ações", as omissões, como formas de manifestação de políticas, pois representam opções e orientações dos que ocupam cargos.

A crise dos anos 70, que provocou iniciativas de reestruturação econômica e a reconfiguração das estratégias empresariais, introduziu, já no início dos anos 80, no debate sobre o Estado contemporâneo, questões relativas às necessidades de incorporação de novos papéis, de abandono de outros e, sobretudo, a exigência de reorganização para enfrentar a crise e adequar-se aos novos requerimentos. Essa crise, em que pese a preponderância da dimensão financeira, coloca em ques-

17 LIMA, O. P. de. Localização geodésica da linha da preamar média de 1831LPM/1831, com vistas à demarcação dos terrenos de marinha e seus acrescidos. 2002. 237 f. Tese (Doutorado em Engenharia Civil) - UFSC, Florianópolis, 2002.

18 RIBEIRO, E. M.; RIBEIRO, M. M.; SANTOS, R. S. Administração Pública Contemporânea e as Singularidades Brasileiras. 2017, p. 36. Disponível em: <https://educapes. capes.gov.br/bitstream/capes/174972/2/eBook_Adm_Publica_Contemporanea_e_as_Singularidades_Brasileiras-Especializacao_em_Gestao_de_Pessoas_UFBA.pdf $>$. Acesso em: em 10 ago. 
tionamento o modo tradicional de organização e gestão governamental, a partir do esgotamento do modelo burocrático de administração pública vigente. Como consequência, isso vem produzindo um déficit de desempenho em termos da baixa qualidade na prestação dos serviços aos cidadãos, que é a dimensão da crise percebida pelo cidadão. Inicialmente na Grã-Bretanha, e depois adotada, quase que de forma generalizada, em diversos outros países, a estratégia de enfrentamento ficou conhecida como a New Public Management (Nova Gestão Pública $-\mathrm{NGP}) .^{19}$

O desafio de promover mudanças necessárias impõe ao Estado a necessidade de repensar a questão da governança e dos modelos de gestão, ao mesmo tempo em que vai exigir mecanismos inovadores de relacionamento com a sociedade. A emergência do terceiro setor e dos movimentos sociais, além dos movimentos que têm como base o voluntariado, vem introduzindo elementos desafiadores nessa nova configuração em rede que caracteriza o Estado contemporâneo. O objetivo é comum e trata, fundamentalmente, de encontrar alternativas para superar as desigualdades, ampliando o espaço de inclusão na vida social, política e econômica na direção do desenvolvimento, a partir da internalização/fortalecimentos dos conceitos de cidadania, equidade e transparência, além da temática própria da gestão contemporânea, que supõe maior eficiência e qualidade no tratamento do interesse público.

Segundo destacado por O'Connor (1977, p. ), o Estado capitalista contemporâneo passou a assumir funções complexas e muitas vezes contraditórias: a de garantir o processo de acumulação e a de garantir a legitimação social. Isso quer dizer que o Estado passou progressivamente na contemporaneidade, especialmente a partir da Segunda Guerra Mundial, a tentar manter ou criar as condições ideais para que ocorra uma lucrativa acumulação do capital, mas sem desconsiderar a necessidade de manter ou criar as condições de "harmonia social" reduzindo, dessa forma, as tensões ou os conflitos sociais. ${ }^{20}$

De encontro ao que fora destacado por O'Connor, no parágrafo anterior, em junho de 2020 foi publicada a Lei $\mathrm{n}^{-}$14.011, que tem como alvo prioritário da medida os chamados imóveis "vagos e sem uso" para a Administração Pública, ou seja, aqueles que não estão sendo ocupados por órgãos públicos. A Secretaria de Coordenação e Governança do Patrimônio da União (SPU) mapeou 3.800 imóveis nesta situação. Se forem todos vendidos, o potencial de arrecadação é de $\mathrm{R} \$ 30$ bilhões nos próximos três anos. Contudo, em razão de tratar-se de uma norma recém publicada e sem dados e informações sobre sua aplicação, não será objeto de análise neste trabalho. ${ }^{21}$

19 MARINI, C. O contexto contemporâneo da administração pública na América Latina. 2002. Revista do Serviço Público - RSP, 31 - 52; Disponível em: <http:// capa.tre-rs.gov.br/arquivos/MARINI_Contexto.pdf>. Acesso em: 30 jul. 2020.

20 RIBEIRO, E. M.; RIBEIRO, M. M.; SANTOS, R. S. Op. Cit., p. 39.

21 BISPO, F. Sancionada lei que moderniza a gestão de imóveis da União. 2020. Disponível em: <https://www.gov.br/economia/pt-br/assuntos/noticias/2020/junho/sancionada-a-lei-que-moderniza-a-gestao-de-imoveis-da-uniao-1>. Acesso em: 15 ago. 2020. 
Entretanto, na direção de uma política pública mais inclusiva e de uma gestão pública mais eficiente, em dezembro de 2015 foi publicada a Lei no 13.240, que além de alterar a alíquota da taxa de ocupação e de laudêmio, incluiu a previsão de repasse de $20 \%$ da receita patrimonial decorrente da alienação dos imóveis em terrenos de marinha aos Municípios onde estão localizados.

A arrecadação desse recurso, até ano de 2016, não era compartilhada junto aos Estado e Municípios. Entretanto, o art. 27, da Lei no 13.240/15, modificou o Decreto-Lei n⿳⺈ 2.398/87, ao instituir o art. 6⿳⺈-B, que estabelece a obrigatoriedade no repasse de $20 \%$ dos recursos arrecadados por meio da cobrança de taxa de ocupação, foro e laudêmio aos Municípios e ao Distrito Federal onde estão localizados os imóveis que deram origem à cobrança. O Parágrafo Único do caput do artigo, define que o repasse serão realizados até o $1^{\underline{0}}$ de fevereiro do ano subsequente ao recebimento dos recursos.

A título de exemplificativo, no dia $1^{\circ}$ de fevereiro de 2017, foi creditado na conta dos Municípios de Santa Catarina, vide tabela 1, os valores referentes exercício de 2016, da arrecadação pertinente a taxa de ocupação, foro e laudêmio dos imóveis pertencentes à União.

Tabela 1. Valores Repassados aos Municípios Catarinenses

\begin{tabular}{|c|c|c|c|c|c|}
\hline Associação & Municípios & Valores & Associação & Municípios & Valores \\
\hline AMAI & Abelardo Luz & 565,87 & AMUREL & Imarui & $2.264,52$ \\
\hline AMUNESC & Araquari & $48.406,50$ & AMUREL & Imbituba & $89.567,64$ \\
\hline AMESC & Araranguá & $34.368,84$ & AMFRI & Itajaí & $450.691,37$ \\
\hline AMESC & Balneário Arroio do Silva & $2.722,50$ & AMFRI & Itapema & $713.729,77$ \\
\hline AMUNESC & Balneário Barra do Sul & $11.874,41$ & AMUNESC & Itapoá & $53.416,15$ \\
\hline AMFRI & Balneário Camboriú & $2.745 .016,03$ & AMUREL & Jaguaruna & 591,32 \\
\hline AMFRI & Balneário Piçarras & $39.839,04$ & AMUNESC & Joinville & $248.826,52$ \\
\hline AMVALI & Barra Velha & $67.591,40$ & AMUREL & Laguna & $176.855,32$ \\
\hline GRANFPOLIS & Biguaçu & $52.794,67$ & AMFRI & Navegantes & $157.187,52$ \\
\hline AMMVI & Blumenau & $26.225,69$ & GRANFPOLIS & Palhoça & $251.391,60$ \\
\hline AMFRI & Bombinhas & $443.421,10$ & AMESC & Passo de Torres & $4.162,60$ \\
\hline AMFRI & Camboriú & $1.053,13$ & AMFRI & Penha & $249.600,46$ \\
\hline GRANFPOLIS & Florianópolis & $1.535 .549,96$ & AMFRI & Porto Belo & $1.379 .701,51$ \\
\hline GRANFPOLIS & Garopaba & $122.050,11$ & AMUNESC & São Francisco do Sul & $203.388,48$ \\
\hline AMUNESC & Garuva & $14.172,56$ & AMESC & São João do Sul & $5.303,39$ \\
\hline AMMVI & Gaspar & $19.908,58$ & GRANFPOLIS & São José & $837.542,43$ \\
\hline GRANFPOLIS & Governador Celso Ramos & $254.864,93$ & AMESC & Sombrio & 258,32 \\
\hline AMREC & Içara & $5.813,07$ & GRANFPOLIS & Tijucas & $8.383,65$ \\
\hline AMFRI & Ilhota & $1.419,92$ & & & \\
\hline \multicolumn{3}{|c|}{ Total } & \multicolumn{3}{|c|}{$10.260 .520,88$} \\
\hline
\end{tabular}

Fonte: SPU - Elaboração: FECAM

No Brasil, também em 2017, foram repassados cerca de $\mathrm{R} \$ 92.56$ milhões para 492 Municípios. Já em Santa Catarina, 37 Municípios receberam esse recurso, totalizando $\mathrm{R} \$ 10.260 .520,88$. Desse montante catarinense, $82,91 \%$ referiu-se a taxa de ocupação, $9,42 \%$ do foro e 1,99\% laudêmio.

A SPU informou que os recursos creditados são de livre aplicação pelos Municípios, ou seja, podem ser destinados a quaisquer ações 
que necessitam de aporte financeiro. ${ }^{22}$

E é na livre aplicação desses recursos pelos Municípios que se encontra a primeira incoerência da política pública advinda da Lei. $\mathrm{n}^{\mathrm{o}}$ 13.240/15. O reconhecimento por parte da União da desentralização da gestão dos imóveis localizados em terrenos de marinha com o repasse de parte dos valores arrecadados aos Municípios que deram origem à cobrança, dando maior autonomia para manutenção e gestão desses imóveis, vai de encontro aos preceitos de gestão e política pública contemporâneos, ressaltados ao longo do texto (maior eficiência, qualidade no tratamento do interesse público e etc...).

Contudo, ao não regular a forma de aplicação desses recursos pelos Municípios, permitindo que destinem a quaisquer ações que necessitem de aporte financeiro, faz com que não haja a obrigação de utilizar os recursos para a gestão dos terrenos de marinha, nem preze pelo exercício da sua função social.

Conforme sustentado por D'Ascenzi e Lima (2013, p.21) a política pública é uma sequência de atos distintos, sendo a formulação da política pública, uma, e sua execução, outra. E é justamente neste ponto que se encontra o maior problema da criação versus implementação de uma política pública, a falta de interação entre essas duas etapas, aplicadas por agentes diversos, que interpretam cada qual a sua realidade e exercidas ou executadas de maneira totalmente desconexa com a política criada, devido à falta de variáveis e entrosamento desses dois grupos.

Os terrenos de marinha, compreendidos como bens do estado que devem objetivar o atingimento das finalidades coletivas, não podem mais ser considerados apenas como meio para arrecadar receita patrimonial aos cofres da União. Conforme discorre Machado (1995), de um lado há o avanço das ciências da natureza e, de outro lado, o povoamento intenso e desordenado do litoral, as áreas de terrenos de marinha necessitam desempenhar funções públicas de proteção da natureza. Essas funções constituem dever do Poder Público, máxime na zona costeira.

\section{CONSIDERAÇÕES FINAIS}

Não é rara a confusão acerca do real significado do termo terrenos de marinha. Esse instituto centenário até hoje é um assunto de difícil entendimento e de inúmeros questionamentos. Infelizmente, a ausência de sistematização da matéria, a tecer enorme concha de retalhos, para além do excesso de burocratização, faz com que o aprofundamento desse estudo seja de extrema importância para simplificar o seu entendimento.

22 VEDANA, C.; FIUZA, A. Comunicado $\mathbf{n}^{\circ}$ 23/2017, expedido pela Federação Catarinense de Municípios (FECAM). Disponível em: <https://static.fecam.net. br/uploads/1670/arquivos/912246_Comunicado_n_0232017__Arrecadacao_de_Receitas_Patrimoniais_da_Uniao.pdf $>$. Acesso em: 10 ago. 2019. 
A orla marítima e os terrenos de marinha sempre foram importantes para o país. Entretanto, no passado, a ênfase era dada à defesa nacional, sendo que hoje, além do cunho arrecadatório, é voltada para o uso e ocupação pela população. Tal realidade carece de ações de gerenciamento costeiro que busquem harmonizar o anseio humano, com a urgente necessidade de considerar a proteção das áreas naturais remanescentes, garantindo o cumprimento da função socioambiental do Patrimônio da União, ressaltando sua articulação com as políticas de inclusão social versus seu equilíbrio com a função arrecadadora.

O desuso da política original e a transformação ao longo do tempo de seus princípios e objetivos, não foi acompanhada por atualizações legislativas, carecendo de uma(s) política pública contemporânea, capaz de trazer conceitos modernos, pautados em interpretações consistentes e condizentes com a real necessidade da prática atual, desburocratizando sua efetiva execução e tornando seus limites de demarcação mais precisos (que viabilize, inclusive, a fiscalização por parte da população).

Pela premissa que empreender uma gestão pública eficiente e efetiva é uma necessidade atual, ao se contrastar os conceitos contemporâneos de gestão e políticas públicas, não vislumbra-se sintonia com a realidade do instituto terrenos de marinha, pois conforme demostrado ao longo do texto, ao passo que de um lado a União avança ao repassar parte da receita arrecadada aos Municípios para que possam melhor gerir e administrar as necessidades locais envolvendo terrenos de marinha, de outro, silencia quanto a aplicação desses recursos, criando uma lacuna na norma, permitindo que os Municípios possam dar a destinação que bem entender a esses recursos, sem prestar contas à União e sem ter nenhuma forma de controle.

Uma forma de suprir esta lacuna seria a criação, por parte dos Municípios, de uma lei específica que preveja a destinação do valor creditado pela União, proporcionando ferramentas que viabilizem o exercício da função social atinente aos terrenos de marinha, bem como possibilite a fiscalização e acompanhamento da aplicação desses recursos pela população e também pela União. Caso contrário, continuará sendo recorrente a falta de interação entre as etapas de criação e a implementação da política, permitindo que cada agente exerça e execute como melhor lhe convir, geralmente desconexa com o objetivo para a qual foi criada.

Este estudo, longe de trazer a solução, visa inaugurar um debate acerca da política pública dos terrenos de marinha frente aos conceitos de gestão e política pública contemporâneos, permitindo trazer uma reflexão sobre essa temática e contribuindo, ainda que de forma simplória, para o estudo desse tema tão pouco explorado/estudado pela doutrina pátria. 


\section{REFERÊNCIAS}

BISPO, F. Sancionada lei que moderniza a gestão de imóveis da União. 2020. Disponível em: <https://www.gov.br/economia/ptbr/assuntos/noticias/2020/junho/sancionada-a-lei-que-modernizaa-gestao-de-imoveis-da-uniao-1>. Acesso em: 15 ago. 2020.

BRASIL, Constituição Federal de 1988. Disponível em: <http://www.planalto.gov.br/ccivil_03/constituicao/ constituicao.htm>. Acesso em: 11 fev. 2016.

Decreto Lei no 9.760/46. Dispõe sobre os bens imóveis da União e dá outras providências. Disponível em: $<$ http://www.planalto.gov.br/ccivil 03/ decreto-lei/De19760.htm>. Acesso em: 17 fev. 2016.

Decreto Lei no 9.636/98. Dispõe sobre a regularização, administração, aforamento e alienação de bens imóveis de domínio da União. Disponível em: <http://www.planalto. gov.br/ccivil_03/leis/19636.htm>. Acesso em: 10 jul. 2020.

Gestão do Patrimônio Imobiliário: Terrenos de Marinha. Disponível em: $<\underline{\text { http://www.planejamento. }}$ gov.br/apresentacoes/apresentacoes-2015/apresentacaocdrsenado-090915.pdf >. Acesso em: 04 dez. 2015.

Lei. no 7.661/88. Institui o Plano Nacional de Gerenciamento Costeiro e dá outras providências. Disponível em: <http://www.planalto.gov.br/ccivil_03/ LEIS/L7661.htm>. Acesso em: 24 mar. 2016.

Lei. no $\mathbf{n}^{\mathbf{0}}$ 3.240/15. Dispõe sobre a administração, a alienação, a transferência de gestão de imóveis da União e seu uso para a constituição de fundos. Disponível em: <http://www.planalto.gov.br/ccivil 03/Ato20152018/2015/Lei/L13240.htm>. Acesso em: 24 mar. 2016.

Lei. $\mathbf{n}^{\mathbf{0}} \mathbf{1 3 . 1 3 9 / 1 5}$. Dispõe sobre o parcelamento e a remissão de dívidas patrimoniais com a União; e dá outras providências. Disponível em: $<\underline{\mathrm{http}} / / /$ www.planalto.gov.br/ccivil 03/ Ato2015-2018/2015/ Lei/L13139.htm>. Acesso em: 24 mar. 2016.

Lei. $\mathbf{n}^{\mathbf{0}} \mathbf{1 4 . 0 1 1 / 2 0}$. Aprimora os procedimentos de gestão e alienação dos imóveis da União. Disponível em: <https://www.in.gov.br/en/web/dou/-/lei-n-14.011-de-10de-junho-de-2020-261279450>. Acesso em: 15 ago. 2020. 
gov.br/ccivil 03/leis/L7661.htm>. Acesso em: 11 fev. 2016.

BRESSER-PEREIRA, L. C. Democracia, Estado Social e Reforma Gerencial. RAE. São Paulo, v. 50. n.1. jan/mar. 2010.

CAVALCANTI, T. B. Tratado de Direito Administrativo. 5. ed. Rio de Janeiro: Freitas Bastos, 1964.

COIMBRA, G. Q.; KRHLING, A. Terrenos de marinha e acrescidos: novas perspectivas para o debate.2015.

Disponível em: <http://docplayer.com.br/7079474Terrenos-de-marinha-e-acrescidos-novas-perspectivaspara-o-debate-1.html >. Acesso em: 11 fev.2016.

D'ASCENZI, L.; LIMA L. Implementação de políticas públicas: perspectivas analíticas. Revista de Sociologia e Política, v. 21, n. 48, p. 101-110, dez. 2013. Disponível em: <https://www.scielo. br/pdf/rsocp/v21n48/a06v21n48.pdf > . Acesso em: 30 jul. 2020.

LEIVAS, L. C. P. Terrenos de Marinha e Terrenos da Marinha: do patrimônio nacional às origens do patrimônio naval. Revista Marítima brasileira/ serviço de documentação geral da marinha, 10/12, 111-119, ISSN 0034 - 9860. 1977.

LIMA, A. J.; CHICUTA K.; JACOMINO, S. Terrenos de Marinham Instituto Jurídico tipicamente brasileiro. IRIB. Sergio Antônio Fabris Editor. Porto Alegre, 2003, p. 30.

LIMA, O. P. de. Localização geodésica da linha da preamar média de 1831- LPM/1831, com vistas à demarcação dos terrenos de marinha e seus acrescidos. 2002. $237 \mathrm{f}$. Tese (Doutorado em Engenharia Civil) - UFSC, Florianópolis, 2002.

MACHADO, P. A. L. Direito ambiental

brasileiro. 5. ed. Malheiros Editores, 1995.

MACHADO, V.B. Mapeamento e análise de obras de engenharia costeira no litoral do Estado de Santa Catarina. 2010. 229f. Monografia de Conclusão de Curso (Bacharel em Oceanografia) - Universidade do Vale do Itajaí. 2010.

MARINI, C. O contexto contemporâneo da administração pública na América Latina. 2002. Revista do Serviço Público - RSP, 31 - 52; Disponível em: <http://capa.tre-rs.gov.br/ arquivos/MARINI Contexto.pdf $>$. Acesso em: 30 jul. 2020.

MORAES, L. Com crescimento de $81 \%$ em sete anos, taxas de Marinha são questionadas na Justiça. 2019. Disponível em: $<$ https://jc.ne10.uol.com.br/canal/economia/ pernambuco/noticia/2019/08/11/com-crescimento-de-81 porcento-em-sete-anos-taxas-da-marinha-sao-questionadas- 
na-justica--385266.php>. Acesso em: 10 ago. 2020.

OLIVEIRA, J. E. A. de. Aforamento e cessão dos terrenos de marinha. Ed. Fortaleza: Imprensa Universitária do Ceará. 1966.

PASSOS, T. Terras de marinha. Leme/SP: Mundo Jurídico. 2013.

QUINTAS, J. S. Educação No Processo De Gestão Ambiental: Uma Proposta De Educação Ambiental Transformadora E Emancipatória. Brasília, Edições IBAMA, 2002.

RIBEIRO, E. M.; RIBEIRO, M. M.; SANTOS, R. S.; Administração Pública Contemporânea e as Singularidades Brasileiras. 2017, p. 39. Disponível em: $<$ https://educapes.capes.gov.br/bitstream/ capes/174972/2/eBook Adm Publica Contemporanea e as Singularidades Brasileiras-Especializacao em Gestao de Pessoas UFBA.pdf $>$. Acesso em: 10 ago. 2020.

RODRIGUES, Rodrigo Marcos Antônio. Curso de terrenos de marinha e seus acrescidos. São Paulo. Nelpa, 2012.

ROMITI, M. M. Terrenos de Marinha. Revista do Advogado. São Paulo. Associação dos Advogados de São Paulo, n. 62, 2001.

SECOVIRIO. Um olho no mar outro na escritura. 2016. Disponível em: <http://www.secovirio.com.br/Noticias/ Noticias/Um-olho-no-mar,-outro-na-escritura-10985. html?tpl=printerview $>$. Acesso em: 20 abr. 2016.

TEIXEIRA, E. C. O papel das políticas públicas no desenvolvimento local e na transformação da realidade. Revista AATR, 2002. Disponível em: <http:// pt.scribd.com/doc/57253448/03- Aatr-Pp-PapelPoliticas-Publicas>. Acesso em: 21 out. 2019.

VEDANA, C.; FIUZA, A. Comunicado $n^{\circ}$ 23/2017, expedido pela Federação Catarinense de Municípios (FECAM). Disponível em: <https://static.fecam.net.br/uploads/1670/ arquivos/912246 Comunicado n 0232017 Arrecadacao de Receitas Patrimoniais da Uniao.pdf >. Acesso em: 10 ago. 2019.

ZIMMERMANN, C.C. Análise da ocupação predial em terrenos de marinha utilizando técnicas de sensoriamento remoto. 1993. 124f. Dissertação (Mestrado em Engenharia Civil) - UFSC, Florianópolis, 1993. 